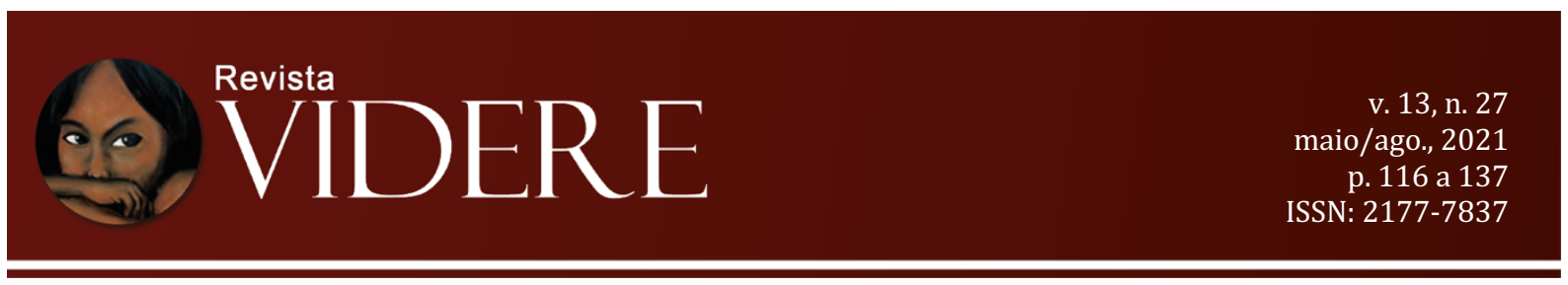

\title{
IMPLICAÇÕES NO ÍNDICE DE DESENVOLVIMENTO HUMANO (IDH) A PARTIR DA PERSPECTIVA DE REVOGAÇÃO DA ZONA FRANCA DE MANAUS/AM: INDICADORES DE DESENVOLVIMENTO HUMANO PARA O PERÍODO 2018-2022
}

\author{
IMPLICATIONS FOR THE HUMAN DEVELOPMENT INDEX (IDH) FROM THE \\ PERSPECTIVE OF REVOCATION OF THE FREE ZONE OF MANAUS, AMAZONAS, \\ BRAZIL: HUMAN DEVELOPMENT INDICATORS FOR THE PERIOD 2018-2022
IMPLICAZIONI SULL'INDICE DI SVILUPPO UMANO (HDI) DALLA PROSPETTIVA DI REVOCA DELLA ZONA LIBERA MANAUS / AM: INDICATORI DI SVILUPPO UMANO PER IL PERIODO 2018-2022

Tatiane Campelo da Silva Palhares Doutora em Direito Constitucional pela Universidade de Fortaleza (UNIFOR) Universidade de Fortaleza (UNIFOR) tatianepalhares@hotmail.com OrcidID: https://orcid.org/0000-0003-0666-9891

\begin{abstract}
Resumo: Este ensaio analisa as implicações no Índice de Desenvolvimento Humano (IDH) a partir da perspectiva de revogação da Zona Franca de Manaus sob a ótica do direito constitucional tributário. Quanto ao objetivo geral, tem-se: analisar, no âmbito da Súmula ${ }^{\circ}$ 615 do STF e do princípio da anterioridade tributária, as implicações da revogação do ICMS para o desenvolvimento humano do Estado do Amazonas. Quanto aos objetivos específicos: a) estudar o aspecto legal, doutrinário e de súmulas, especificamente a 615-STF, e do princípio da anterioridade tributária sobre implicações em face do IDH; b) construir cenários para avaliar as implicações da revogação ou não do ICMS no modelo da Zona Franca de Manaus; c) estimar, a partir da construção de cenários, as variações nas estatísticas selecionadas de desenvolvimento humano para o ano de 2022. Quanto à metodologia, destaca-se na pesquisa o método quantiqualitativo. A pesquisa quantitativa busca compreender a coleta de dados numéricos, comportamentos e outras ações dos indivíduos que pertencem a determinados grupos ou sociedade. Para definição da população e da amostra, decidiu-se trabalhar com os dados extraídos dos Censos Demográficos, Pesquisa Nacional por Amostra de Domicílios (PNAD) e Contas Regionais por meio dos sistemas de dados agregados (DataSus, Ipeadata, Estados/IBGE e E-SIGA/CEDECTI-AM). Por fim, equaciona-se o seguinte questionamento: a revogação da isenção do ICMS na Zona Franca de Manaus/AM (ZFM) pode contribuir para a redução do padrão do Índice de Desenvolvimento Humano (IDH) no Estado do Amazonas/AM?
\end{abstract}


Palavras-chave: Índice de Desenvolvimento Humano. Zona Franca de Manaus. direito constitucional tributário. revogação de incentivo tributário - ICMS.

Abstract: This essay analyzes the implications for the Human Development Index (IDH) from the perspective of revoking the Manaus Free Trade Zone from the perspective of constitutional tax law. As for the general objective, we have to: analyze, within the scope of the 615 summary of the STF and the principle of tax precedence, the implications of the revocation of the ICMS for the human development of the State of Amazonas. As for the specific objectives: a) to study the legal, doctrinal and summary aspects, specifically 615-STF and the principle of tax precedence; $b$ ) build scenarios to assess the implications of the revocation or not of the ICMS in the Manaus Free Zone model; c) estimate, from the construction of scenarios, the variations in the selected human development statistics for the year 2022. As for the methodology, the quantitative and qualitative method stands out in the research. Quantitative research seeks to understand the collection of numerical data, behaviors and other actions of individuals who belong to certain groups or society. To define the population and the sample, it was decided to work with the data extracted from the Demographic Census, National Household Sample Survey (PNAD) and Regional Accounts through the aggregated data systems (DataSus, Ipeadata, States/IBGE and E-SIGA/CEDECTI-AM). Finally, to equate the answer based on the question: can the revocation of the exemption from ICMS in the Manaus Free Trade Zone (ZFM) contribute to the reduction of the Human Development Index (IDH) pattern in the State of Amazonas/AM?

Keywords: Human Development Index. Manaus Free Zone. constitutional tax Law. revocation of tax incentive - ICMS.

Astratto: Questo saggio analizza le implicazioni per l'indice di sviluppo umano (HDI) dal punto di vista della revoca della zona di libero scambio di Manaus dal punto di vista della legge fiscale costituzionale. Per quanto riguarda l'obiettivo generale, dobbiamo: analizzare, nell'ambito del precedente n. 615 dell'STF e del principio di precedenza fiscale, le implicazioni della revoca dell'ICMS per lo sviluppo umano dello Stato di Amazonas. Quanto agli obiettivi specifici: a) approfondire gli aspetti legali, dottrinali e di sintesi, nello specifico il 615-STF, e il principio di precedenza fiscale sulle implicazioni in vista dell'ISU; b) costruire scenari per valutare le implicazioni della revoca o meno dell'ICMS nel modello della zona franca di Manaus; c) stimare, dalla costruzione degli scenari, le variazioni nelle statistiche di sviluppo umano selezionate per l'anno 2022. Per quanto riguarda la metodologia, spicca nella ricerca il metodo quanti-qualitativo. La ricerca quantitativa cerca di comprendere la raccolta di dati numerici, comportamenti e altre azioni di individui che appartengono a determinati gruppi o società. Per definire la popolazione e il campione si è deciso di lavorare con i dati estratti dal Demographic Census, National Household Sample Survey (PNAD) e Regional Accounts attraverso i sistemi di dati aggregati (DataSus, Ipeadata, States / IBGE e E-SIGA / CEDECTIAM). Infine, viene affrontata la seguente domanda: la revoca dell'esenzione dall'ICMS nella Manaus Free Trade Zone (AMZ) può contribuire alla riduzione del modello dell'Indice di sviluppo umano (HDI) nello Stato di Amazonas / AM?

Parole chave: Indice di Sviluppo Umano. Zona Franca di Manaus. diritto tributario costituzionale. revoca degli incentivi fiscali - ICMS. 


\section{Introdução}

A cidade de Manaus/AM e sua função como centro urbano do Estado do Amazonas só podem ser compreendidas levando-se em conta que é preciso remontar a meados do século XVII, com base no lastro de uma ação militar e comercial de Portugal com a finalidade de afastar concorrentes ingleses, holandeses e franceses que se apoderavam das drogas do sertão (canela, cravo, raízes oleaginosas, madeiras) e, por extensão, das potencialidades produtivas.

A economia amazônica, altamente dependente do comércio exterior, experimentou ligeiro avanço, em meados do século XVIII, caracterizado pelo incentivo à agricultura. A emergência do ciclo agrícola, ocorrido nesse século, produziu cacau, café, algodão e cana-deaçúcar. O cacau, em 1740, representou mais de 90\% das exportações regionais (FERREIRA, 2003).

No período pombalino (1750-1777), sobreveio um reforço à agricultura e às plantações de cacau, algodão, café, arroz e canela, as quais apresentaram um sensível crescimento. Entretanto, o volume da produção extrativista continuava ainda inferior. A economia amazônica, desde os fins do século XVIII, entrou em decadência tendo em vista a desorganização do sistema de exploração de mão de obra indígena, estruturado pelos jesuítas. Ante a ação de Pombal, expulsando-os, a região reverteu um estado de crise econômica.

O processo de produção e comercialização que se designa na economia da borracha, cujas condições de acumulação e crescimento levaram à reiteração extrativista da Amazônia, atingiu o auge de exportação entre 1880 e 1912. Trata-se de uma economia identificada com uma etapa monopolista que procurava mais que a vantagem comercial, mas sim o custo menor e a expansão imperialista.

O crescimento da produção da borracha amazônica procurou acompanhar a demanda externa. Porém, à medida que esse produto era solicitado no mercado internacional, os seringais da Amazônia eram devastados pelo fluxo de mão de obra que utilizava os métodos de extração mais rudimentares.

A baixa dos preços da borracha no mercado internacional, que se acentuou após a $1^{\mathrm{a}}$ Guerra Mundial (1914-1918), determinou a desvalorização do único produto que, por alguns anos, garantiu a economia da região amazônica. A fisionomia de uma cidade em decadência era estampada nos jornais acompanhada da evolução de um passado de prosperidade. A atividade portuária tão intensa na década precedente estava desativada, os preços cada vez mais elevados; além disso, a falta de transporte e a exiguidade de rendas indicavam que o período da borracha havia terminado. 
Os comerciantes, através da Associação Comercial do Amazonas, continuavam a solicitar ajuda ao Governo Federal como a única fonte capaz de salvar a situação. As quedas dos preços da borracha marginalizavam a Amazônia, empobrecendo cada vez mais as oligarquias que dominavam a região. Essa situação provocava divergências entre os grupos que apenas procuravam manipular o poder para servir aos seus interesses particulares.

Nesse compasso, a Zona Franca de Manaus foi regulamentada pelo Decreto-Lei $n^{\circ}$ 288/1967, concebida como área de livre comércio de importação, exportação e incentivos fiscais, especiais, tendo a finalidade de criar no interior da Amazônia um centro industrial, comercial e agropecuário dotado de condições econômicas que permitissem a ocupação e o desenvolvimento da região.

Assim, justifica-se o tema pela importância das implicações em face do Índice de Desenvolvimento Humano (IDH), a partir da revogação do incentivo da isenção tributária referente aos impostos, especificamente relativo ao ICMS, que, por natureza, é não cumulativo. Logo, como garantia do cumprimento do princípio da anterioridade tributária, deve o contribuinte e cidadão amazonense arcar com o aumento da mercadoria em função do restabelecimento do imposto. Entende-se, em função de correntes divergentes, que isso não deverá ser restabelecido com margem a uma possível majoração, fato que só poderá ocorrer por meio de lei.

O objetivo geral deste ensaio pauta-se na análise, no âmbito da Súmula no 615 do STF e do princípio da anterioridade tributária, sobre as implicações da revogação do ICMS no índice de desenvolvimento humano do Estado do Amazonas. Quanto aos objetivos específicos, temse: a) estudar o aspecto legal, doutrinário e de súmulas, especificamente a 615-STF, e do princípio da anterioridade tributária sobre implicações em face do IDH; b) construir cenários para avaliar as implicações da revogação ou não do ICMS no modelo Zona Franca de Manaus; c) estimar, a partir da construção de cenários, as variações nas estatísticas selecionadas de desenvolvimento humano para o ano de 2022.

No tocante à metodologia, destaca-se a análise qualitativa, que tem como objeto situações complexas ou estritamente particulares. Os estudos que empregam a metodologia qualitativa podem: descrever a complexidade do problema; analisar a interação de certas variáveis; compreender e classificar processos dinâmicos vividos por grupos sociais; contribuir no processo de mudança, assim como no entendimento das particularidades do comportamento dos indivíduos.

Já a pesquisa quantitativa busca compreender a coleta de dados numéricos, comportamentos e outras ações dos indivíduos que pertencem a determinados grupos ou 
sociedade. Para definição da população e da amostra, decidiu-se trabalhar com os dados extraídos dos Censos Demográficos, Pesquisa Nacional por Amostra de Domicílios (PNAD) e Contas Regionais por meio dos sistemas de dados agregados (DataSus, Ipeadata, Estados/IBGE e E-SIGA/CEDECTI-AM).

Quanto à técnica, na abordagem qualitativa, tem-se a análise de conteúdo, pois serão examinados textos doutrinários e normativos, buscando depreender o significado de determinadas expressões e, assim, compreender as entrelinhas do texto. Com isso, procurou-se estudar a unidade de registro e a unidade de contexto dos dados analisados.

Diante disso, de forma a cumprir os objetivos específicos levantados, partiu-se de um planejamento em cenários, uma vez que a revogação do ICMS, até o momento de elaboração deste estudo, em março de 2020, encontra-se em discussão. Logo, torna-se necessário realizar uma análise estratégica do tipo SWOT, na qual são considerados os pontos fortes (strengths), os pontos fracos (weaknesses), as oportunidades (opportunities) e as ameaças (threats).

Tendo como objeto o Estado do Amazonas e, consequentemente, o Modelo Zona Franca de Manaus (ZFM), e a partir de pesquisa bibliográfica e documental, serão definidas variáveis críticas para caracterizar os ambientes internos (forças e fraquezas) e externos (ameaças e oportunidades). Em seguida, esses dados serão atribuídos a esses valores numéricos para diferenciá-los em dois cenários distintos:

- Cenário 1: Não ocorre a revogação do ICMS;

- Cenário 2: Ocorre a revogação do ICMS.

Definidos os cenários, o próximo procedimento é a estimação das variáveis de desenvolvimento humano. Nesse sentido, a escolha destas considera as seguintes dimensões do Índice de Desenvolvimento Humano (IDH): educação, renda e longevidade.

Assim sendo, a educação será representada pela média de anos de estudo para as pessoas de 25 anos ou mais de idade, disponibilizada pela PNAD contínua. Por sua vez, a renda terá como fonte o Produto Interno Bruto per capita disponibilizado pelas Contas Regionais do IBGE. Por fim, a longevidade corresponderá à razão entre o número de óbitos por domicílio e os nascimentos por ocorrência segundo ano de nascimento, oriundos dos Sistemas de Informações sobre nascidos vivos e de mortalidade do Ministério da Saúde.

A previsão dos indicadores de desenvolvimento humano será feita para o período 2018-2022, por meio de um modelo de predição estatístico, considerando os devidos testes de significância e de erro. Em paralelo, de forma a constatar a significância estatística das variáveis estudadas, deverá ser realizada uma matriz de correlação. 
Verificado o impacto das variáveis do ponto da correlação, será realizada a regressão linear múltipla ${ }^{1}$ com o propósito de prever o efeito das variáveis de desenvolvimento humano no ICMS recolhido pelo Polo Industrial de Manaus, cuja estrutura se dá na forma que segue:

$$
\operatorname{lnICMS}-\operatorname{Rec}=\alpha+\beta_{1} \ln \text { PIBpc }+\beta_{2} \ln \mathrm{AE}+\beta_{3} \ln \text { Long }+\beta_{4} \ln \text { Pop (1) }
$$

Segundo esse modelo, lnICMS-Rec é a variável explicada e representada pelo ICMS recolhido das atividades do Polo Industrial de Manaus, enquanto $\ln$ PIBpc, $\ln \mathrm{AE}$, $\ln L o n g$ e lnPop correspondem ao Produto Interno Bruto per capita, anos de estudo, razão entre óbitos e nascidos vivos e população do Estado do Amazonas, respectivamente. Todas as informações estão organizadas sob a forma de logaritmos para permitir uma análise não apenas no sentido das relações entre as variáveis, mas também do ponto de vista do quão sensível o ICMS recolhido é em relação às demais.

Da mesma forma, torna-se importante verificar a sensibilidade das variáveis de desenvolvimento humano em relação ao ICMS recolhido pelo Polo Industrial de Manaus (PIM). Isso posto, serão elaboradas três regressões simples ${ }^{2}$, sendo:

$$
\begin{aligned}
& \ln \mathrm{PIBpc}=\alpha+\beta_{1} \operatorname{lnICMS}-\operatorname{Rec}(2) \\
& \ln \mathrm{AE}=\alpha+\beta_{1} \operatorname{lnICMS}-\operatorname{Rec}(3) \\
& \operatorname{lnLong}=\alpha+\beta_{1} \operatorname{InICMS-Rec}(4)
\end{aligned}
$$

Por fim, em se tratando dos testes de significância, serão verificados os valores críticos das estatísticas $\mathrm{F}$ de Fisher e $\mathrm{t}$ de student, em conjunto com os coeficientes de correlação, de determinação R2, R2 ajustado e erro padrão. Por conseguinte, também será realizado o teste de Fatores de Inflação de Variância (VIF) com o intuito de verificar a possibilidade de existência de multicolinearidade nos modelos de previsão.

Os modelos de previsão estruturados permitirão, além da capacidade preditiva dos indicadores para o período 2018-2022, verificar qual variável explicada sofre mais influência das explicativas. Ou seja, se o ICMS recolhido é mais influenciado pelas variáveis de desenvolvimento humano ou o contrário. Isso será constatado a partir da interpretação dos

\footnotetext{
${ }^{1}$ Regressão linear múltipla é uma coleção de técnicas estatísticas para construir modelos que descrevem de maneira razoável relações entre várias variáveis explicativas de um determinado processo. A diferença entre a regressão linear simples e a múltipla é que na múltipla são tratadas duas ou mais variáveis explicativas. Disponível em: $<$ http://www.portalaction.com.br/analise-de-regressao/regressao-linear-multipla $>$. Acesso em: 25 fev. 2020.

2 Regressão linear simples: a análise de regressão estuda a relação entre uma variável, chamada variável dependente, e outras variáveis, chamadas variáveis independentes. A relação entre elas é representada por um modelo matemático que associa a variável dependente com as variáveis independentes. Esse modelo é designado por um modelo de regressão linear simples e se define uma relação linear entre a variável dependente e uma

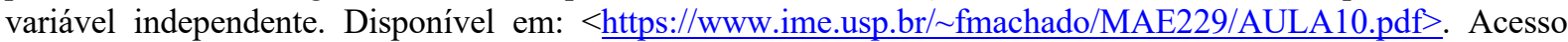
em: 25 fev. 2020.
} 
coeficientes de correlação, bem como dos parâmetros utilizados nos quatro modelos de regressão.

Quanto aos cenários levantados, tais modelos serão considerados para prever as variações no cenário 1, ao passo que, para o segundo, serão incluídas variáveis dummy, a partir da identificação das variáveis críticas para o objeto de estudo.

Assim, este ensaio pauta-se no seguinte questionamento: a revogação da isenção do ICMS na Zona Franca de Manaus/AM (ZFM) pode contribuir para a redução do padrão do Índice de Desenvolvimento Humano (IDH) no Estado do Amazonas/AM?

\section{Implicações para revogação do ICMS na Zona Franca de Manaus}

Com efeito, constitui uma evidência que os impostos são uma instituição onipresente, pois, a rigor, acompanha os indivíduos desde o nascimento até a morte. Pode-se definir imposto com base em três elementos, a saber: "um elemento objetivo, um elemento subjetivo e um elemento teleológico (ou finalista). Objetivamente, o imposto é uma prestação pecuniária unilateral definitiva e coativa" (NABAIS, 2019, p. 34).

Por sua vez, subjetivamente, o imposto é uma prestação com características exigíveis aos contribuintes de capacidade contributiva a favor de entidades que exerçam funções públicas para a realização dessas funções. O imposto é, do ponto de vista objetivo, uma prestação, o que significa que integra uma relação de natureza obrigacional, e não uma relação de caráter real.

O imposto é uma prestação que tem por fonte a lei, que é estabelecida em lei. A obrigação de imposto surge, exclusivamente, por força do encontro do fato gerador com a lei que assim modela seu conteúdo, independentemente, portanto, de qualquer manifestação de vontade do contribuinte nesse sentido. O imposto é, ainda, uma prestação unilateral, não lhe correspondendo assim qualquer contraprestação específica a favor do contribuinte, conforme art. 16 do Código Tributário Nacional - CTN (BRASIL, 1966).

Finalmente, do ponto de vista teleológico ou finalista, o imposto é exigido pelas entidades que exercem funções públicas para realização de suas funções de caráter sancionatório, o que significa que o imposto pode ter por finalidade não apenas a financeira ou fiscal, mas também outras, excluída a função sancionatória.

Com o objetivo de promover o desenvolvimento regional, usualmente, os Estados podem adotar mudanças ou variações no que diz respeito à forma de cobrança de seus impostos. No caso do Estado do Amazonas, a Zona Franca de Manaus teve como foco a criação de um polo de desenvolvimento da Amazônia, a fim de transformá-la em uma base econômica viável 
e rentável. Sua estrutura compõe-se de três polos econômicos: comercial, industrial e agropecuário. No entanto, tem no polo industrial o alicerce de sustentação do modelo (SILVA et al., 2019).

Na Zona Franca de Manaus, são garantidos os seguintes benefícios fiscais às empresas (com algumas exceções): isenção ou redução no Imposto sobre Importação (II); isenção do Imposto de Exportação (IE); isenção ou crédito do Imposto sobre Produtos Industrializados (IPI); redução de 75\% do Imposto de Renda de Pessoas Jurídicas (IRPJ); isenção, crédito ou restituição do Imposto sobre Circulação de Mercadorias e Serviços (ICMS); isenção por 10 anos do IPTU (Imposto sobre a Propriedade Predial, Territorial Urbana), taxa de serviço de limpeza e conservação pública e taxa de licença de funcionamento (SILVA et al., 2019).

No tocante à finalidade financeira, a isenção de impostos na Zona Franca de Manaus (ZFM) pressupõe uma geração de empregos, haja vista que as empresas podem ser atraídas, dentre outros fatores, pelo incentivo da isenção. A possível revogação da isenção do imposto geraria um reestabelecimento da alíquota do imposto, o que prejudicaria o Estado do Amazonas em face de sua economia, e, sobretudo, no Índice de Desenvolvimento Humano.

O ICMS tem como propósito favorecer a indústria e o comércio da ZFM, no que diz respeito à restituição desse imposto pelas empresas industriais fabricantes de produtos prioritários e na isenção do mesmo sobre a exportação de produtos para a ZFM. Também é possível creditar ICMS na energia elétrica consumida do estabelecimento, nos serviços de telefonia e nos serviços de transporte, desde que destacados na nota fiscal.

Em contrapartida, Vasconselos (2019) sugere que o federalismo fiscal brasileiro conduz a um alto grau de autonomia dos Estados, o que dificulta a modernização do ICMS, com base na sistemática de um Imposto sobre o Valor Acrescentado (IVA) uniforme e combinado com as tendências internacionais. Por consequência, como não há harmonização legislativa ou neutralidade tributária, o regime complexo desse imposto estimula uma competição tributária prejudicial entre as províncias e gera tensões federativas, enfraquecendo o pacto federal.

A Constituição Federal brasileira de 1988 também permite que a autoridade legislativa dos Estados regulamente o ICMS. Dessa forma, abre caminho para a existência de uma heterogeneidade de alíquotas de impostos, criando dificuldades para a administração, complexidade no total de impostos pagos pelo contribuinte e fiscalização do imposto, assim como evasão e concorrência fiscal entre os Estados.

Em relação à revogação da isenção de impostos tributários, destaca-se o posicionamento do Ministro Marcos Aurélio, relator no RE 564.225, Agr/RS, de 2/9/2014, 
segundo o qual, uma vez que seja retirada a isenção, haverá o restabelecimento da alíquota em relação ao imposto, fato que provocará um aumento no valor da alíquota e, por isso, precisaria, desde logo, preservar o princípio da anterioridade tributária como forma de garantia de direitos fundamentais.

No que se refere à Súmula $\mathrm{n}^{\circ} 615$ do Supremo Tribunal Federal, in verbis: “o princípio constitucional da anualidade ( $§ 29$ do art. 153 da CF/1967) não se aplica à revogação de isenção do ICMS”. De acordo com Amaro (2011), os fundamentos dessa jurisprudência partem de premissas equivocadas, as quais, mesmo na hipótese de serem assumidas como corretas, não levariam às conclusões que foram firmadas pelo Supremo. O art. 104, no item III, CTN, cuidou adequadamente da matéria quando explicitou que a revogação de isenção de tributo (sujeito à anterioridade) só autoriza a tributação no exercício subsequente. E, mesmo que não o dissesse, não se poderia dar ao Código Tributário Nacional interpretação que pudesse ferir, ainda que indiretamente, um princípio constitucional.

Resta destacar ainda que a entrada de mercadorias estrangeiras na Zona Franca de Manaus, destinadas ao seu consumo interno, industrialização em qualquer grau, inclusive beneficiamento agropecuário, pesca, instalação e operação de indústria e serviços de qualquer natureza e a estocagem para reexportação, será isenta de impostos de importação e sobre produtos industrializados (BRASIL, DECRETO-LEI No 288, 1967). Ressalta-se também que ficam isentas do imposto as saídas de produtos industrializados de origem nacional para comercialização ou industrialização na Zona Franca de Manaus, desde que o estabelecimento tenha domicílio no município de Manaus (BRASIL, CONVÊNIO ICMS Nº 65, 1988).

Verifica-se que todas as fábricas recebem o mesmo tratamento para isenção das espécies de impostos, desde que tenham projeto técnico econômico aprovado pela SUFRAMA e laudos que autorizem a instalação do parque fabril e de produção (laudo de operação e laudo de produção) para incentivos federais, projetos e laudo técnico aprovado pela Secretaria de Estado de Desenvolvimento econômico, Ciência, Tecnologia e Inovação (SEDECTI) para os incentivos estaduais.

Um dos questionamentos relacionados com a ZFM é referente ao surgimento do pacote intitulado por medidas econômicas propostas pelo Governo Federal, o qual prevê um limite para criação de benefícios tributários, prevendo que sejam reavaliados a cada quatro anos para que não ultrapassem o percentual de $2 \%$ do Produto Interno Bruto (PIB) a partir de 2026. O Plano Mais Brasil prevê diversas questões que podem contribuir para o restabelecimento econômico e do IDH, como: a criação do conselho Fiscal da República, cuja responsabilidade 
é monitorar as contas públicas dos entes; e a uniformização de metodologias nas contas públicas, com o intuito de evitar interpretações diferentes nos Tribunais de Contas dos Estados.

\section{Princípio da anterioridade tributária em face do ICMS na Zona Franca de Manaus}

O Ministério da Economia (BRASIL, 2018), a respeito da abrangência da Zona Franca de Manaus (ZFM), esclarece que a expressão 'incentivo fiscal' está relacionada com a conduta de estimular, incitar e instigar. Os incentivos fiscais também podem ser conceituados como o estímulo realizado pelo Governo com parcerias com a iniciativa privada, através de renúncias de receitas públicas, para desenvolver setores importantes no país. Esse tipo de incentivo ganhou destaque no cenário nacional a partir de 1960, porém apenas na década de 1980 observou-se a ampliação e a consolidação dessas políticas em nível federal, com o objetivo de viabilizar o aumento e a efetividade da participação das empresas nas demandas sociais e econômicas (GOLDSTEIN, 2007).

Conforme o artigo 150, III, “b”, CF/1988, é vedado à União, Estados, Distrito Federal e Municípios cobrar tributos no mesmo exercício financeiro em que haja sido publicada a lei que os instituiu ou aumentou. Assim, deve tomar como marco temporal a data da publicação da lei. O princípio existe para proteger o contribuinte, não impedindo, portanto, a imediata aplicação das mudanças que diminuem a carga tributária aplicada ao contribuinte (caso de extinção ou redução de tributos) ou que não tenham qualquer impacto sobre a carga tributária.

Quando determinado contribuinte é "beneficiado" por isenção legalmente concedida, há uma diminuição da carga tributária a que está sujeito, não havendo que se falar em qualquer prazo para que o benefício possa gerar efeitos concretos. Já no caso de revogação de uma isenção concedida, a situação é oposta, pois, indiscutivelmente, a mudança legislativa tem como consequência um acréscimo no sacrifício financeiro pelo contribuinte. Enquanto isenção tributária, entende-se que o caráter cumulativo dos requisitos que caracterizam o tipo de isenção não sujeita à livre revogação (isenção onerosa), uma vez que a Súmula ${ }^{\circ} 544$ do STF destaca que "isenções tributárias concedidas, sob condição onerosa não podem ser livremente suprimidas".

O artigo 178, CTN, disciplina que as restrições à revogação das denominadas isenções onerosas, definidas como aquelas que não trazem somente o bônus da dispensa legal do pagamento, mas também alguns ônus como condição para seu gozo aos contribuintes, não podem ser revogadas ou modificadas a qualquer tempo. E, ainda, teria de se realizar por meio de lei, respeitando o princípio da anterioridade tributária. 
Vale destacar que não se pode confundir a revogação da isenção onerosa (impossível, por conta da proteção do direito adquirido) com a revogação da lei concessória de isenção onerosa (possível, pois não se pode impedir o parlamentar de revogar uma lei). No caso da Zona Franca de Manaus, tem-se uma isenção concessória que tende a prorrogar-se por meio de lei com o passar do tempo.

O primeiro decreto de concepção do porto livre de Manaus foi o Decreto $\mathrm{n}^{\mathrm{o}}$ 3.173/1957. Após 10 anos, a primeira concessão de incentivos fiscais para a Zona Franca de Manaus foi instituída pelo Decreto-Lei no 288/1967 por meio do Decreto no 92.560 de 1986, o qual, em seu artigo $1^{\circ}$, prorrogava-a por 10 anos, ou seja, de 1986 a 1997; a segunda prorrogação se deu em 1988, com a promulgação da Constituição Federal, por meio do artigo 40 dos Atos das Disposições Constitucionais Transitórias (ADCT), que prorrogou até o ano de 2013; a terceira prorrogação se deu por meio da EC42/2003, que modificou o artigo 42 do ADCT, estendendo os incentivos fiscais até 2023; por último, tem-se a quarta prorrogação, que fíca oficialmente prorrogada até o ano de 2073, através da EC83/2014.

O artigo 150, I, CF/1988 admite a concessão de incentivos fiscais destinados a promover o equilíbrio socioeconômico entre as diferentes regiões do país (princípio da uniformização geográfica tributária). Já o artigo 104, III, CTN destaca que entram em vigor, no primeiro dia do exercício seguinte àquele em que ocorra sua publicação, os dispositivos referentes aos impostos sobre o patrimônio ou a renda que extinguem ou reduzem isenções. Para o STF, a revogação de isenção não se equipara à criação ou majoração de tributo, sendo apenas a dispensa legal do pagamento de exação já existente, de forma que o tributo volta a ser imediatamente exigível, não sendo aplicável o princípio da anterioridade (RE 204.062).

Todavia, em entendimento da primeira turma do Superior Tribunal de Justiça, o RE 564.225 Agr/RS vem alterando-o no sentido de que a tendência é que a revogação de qualquer benefício fiscal configura aumento indireto de tributo e, justamente por isso, somente gera efeitos financeiros no exercício subsequente ao da publicação da lei revogadora.

Historicamente, o Decreto-Lei no 288/1967 surgiu com a proposta de beneficiar, por meio de isenção de tributos, as empresas que se instalassem na Zona Franca de Manaus, com o intuito de oportunizar empregos e aumentar o número populacional do Estado do Amazonas, especificadamente na capital Manaus.

Assim, em um retrospecto, primeiramente, cabe considerar a situação de crise vivida pelo Amazonas, no século XVIII, especialmente na cidade de Manaus, diante da queda dos preços da borracha no mercado internacional, o que determinou, em nível local, uma disputa entre interesses políticos. A luta política apresentava lideranças desgastadas, sem unidade 
interna e perdidas em constantes conflitos. Configurava-se, dessa forma, a crise econômica e política.

Aliás, na política econômica nacional, os interesses cafeeiros estavam em primeiro plano. Disso resultavam o desprestigio e a indiferença do poder central para com os problemas do Amazonas. A classe dominante regional, constituída por uma oligarquia, cujos interesses estavam ligados à exportação de produtos florestais, com o fracasso da borracha da região nos mercados internacionais, encontrava-se cada vez mais empobrecida.

A Zona Franca de Manaus (ZFM) torna-se de fundamental importância para os habitantes e para a economia do país. Ressalta-se que os prejuízos tendem a ser maiores quando há a revogação da isenção sem observância do princípio da anterioridade. Feita essa análise, destaca-se, com base nos dados da Superintendência da Zona Franca de Manaus, que os faturamentos são maiores do que os insumos, o que justifica a permanência do incentivo da isenção e a não aceitação da Súmula n ${ }^{\circ} 615$ do STF.

Assim, conforme Gina Pompeu (2012, p. 118), "para aliar o desenvolvimento econômico humano ao desenvolvimento nas esferas local e global, será essencial a presença constante de instituições sociais e do Estado responsável”. Por isso, a constante preocupação em aliar desenvolvimento econômico a desenvolvimento humano é de vital importância, haja vista que as pessoas da região Norte, e não apenas do Estado do Amazonas, utilizam a ferramenta econômica da geração de emprego da Zona Franca de Manaus. Portanto, uma possível revogação do incentivo da isenção referente aos impostos tributários possibilitaria um sério risco do retrocesso na história. Diante disso, tem-se que:

[...] valores humanos devem ser transnacionais atravessar Estados e serem inferidos nas Constituições e ordenamentos jurídicos. Nesse contexto, o mundo deve ser plano. Pondera-se, porém, que para o necessário desenvolvimento local, haja vista, as necessidades locais de cada região (POMPEU, 2012, p. 122).

Dessa forma, os Estados devem refletir que, apesar da Zona Franca de Manaus gerar renda e emprego, os indivíduos, em contrapartida, continuam sendo abandonados em face de prestação de direitos fundamentais básicos, como o direito à educação e à saúde, como destacam os dados do IBGE (último Censo 2010). No que se refere ao IDEB, as escolas públicas, nas séries iniciais, apresentam um percentual de 5,3\% e, nas séries finais, um percentual de $4,4 \%$.

Nesse caso, existe uma necessidade de reavaliar o modelo da Zona Franca de Manaus/AM, pois é necessário dar mais atenção à sociedade e fazer com que a geração de emprego não vise, como fator principal, o lucro, mas sim o desenvolvimento da região. 
Tocqueville (1998) destaca que o grande mal moral é o individualismo, ferrugem da sociedade, que torna o cidadão vazio de toda a essência do civismo e do interesse do bem comum.

3.1 Análise sobre os indicadores amazonenses de desenvolvimento humano

De acordo com a metodologia utilizada pelo Programa das Nações Unidas para o Desenvolvimento (PNUD), o Índice de Desenvolvimento Humano (IDH) é medido nas perspectivas de renda, educação e longevidade. Isso pressupõe que a melhoria na qualidade de vida das pessoas pode ser analisada ao se levar em consideração o quanto a sociedade recebe financeiramente, em paralelo com a média de anos de estudo e sua esperança de vida ao nascer.

Por conseguinte, no Estado do Amazonas, ambiente caracterizado pela presença do Modelo da Zona Franca de Manaus, onde as empresas do Polo Industrial de Manaus que atendem às perspectivas de promoção ao desenvolvimento regional recebem incentivos fiscais no âmbito da Lei Estadual $n^{\circ} 2.826 / 2003$, foram observadas variações positivas nos indicadores selecionados para representar o desenvolvimento humano no período 1997-2017, conforme observado no Gráfico 1.

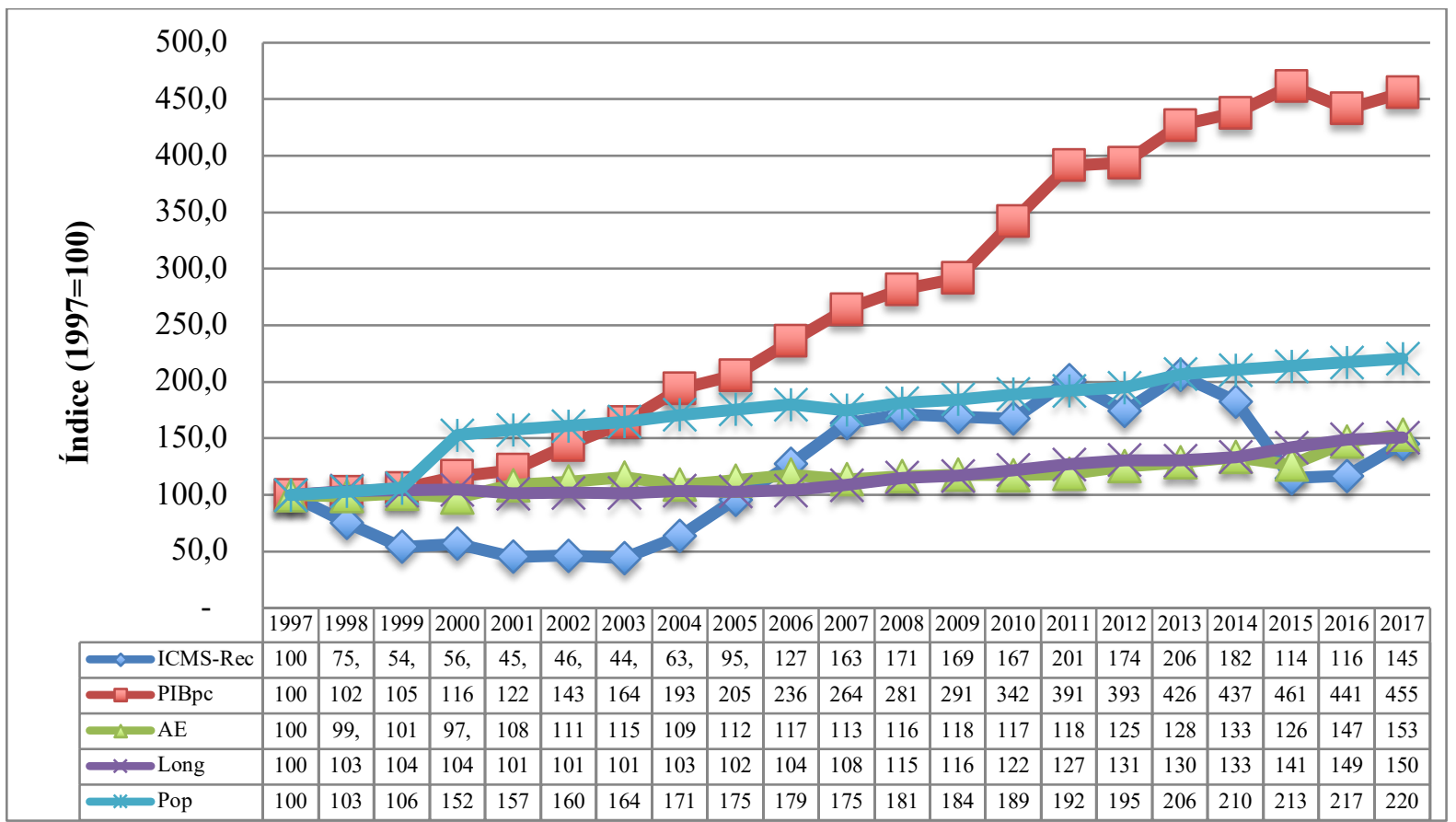

Gráfico 1 - Evolução das variáveis de desenvolvimento humano no Estado do Amazonas período 1997-2017. Fonte: Elaboração própria a partir de dados do IBGE, Suframa e Ministério da Saúde - SINASC/SIM. 
Em termos gerais, verificam-se, na média do período selecionado para esta pesquisa, variações positivas para todas as variáveis. Todavia, as discrepâncias observadas no desempenho destas podem contribuir para a caracterização do padrão de desenvolvimento no Estado do Amazonas.

Primeiramente, o Produto Interno Bruto per capita cresceu, em média, 7,88\% no período. Isso pode estar relacionado com o desempenho significativo que a produção industrial e, consequentemente, o PIM têm na economia amazonense. Em paralelo, na medida em que acontecem eventos de ordem conjuntural, como a crise cambial de 1999 dos Estados Unidos, verificam-se desacelerações, ou seja, crescimento em intensidade menor do que no ano anterior. Por exemplo, o PIB per capita cresceu 6,71\% em 2008, enquanto no ano de 2007 houve uma variação positiva de $11,89 \%$ em relação a 2006.

Dado que todo fluxo de produção possui geração de renda correspondente, é possível considerar que o PIB per capita representa a renda per capita gerada no Estado. Entretanto, não se pode afirmar que a geração de renda é equivalente à sua distribuição.

Parte dos motivos para não fazer tal associação está nos diferenciais de variação percentual do PIB e da população do Estado ao longo do tempo. Em se tratando da última, percebeu-se que esta variou 4,04\%. Essa variação está menos proporcional do que a do PIB per capita. Outro aspecto a ser considerado é a desigualdade na distribuição da renda.

De acordo com os dados sobre Desenvolvimento Humano no Brasil, disponibilizados pelo PNUD, o índice de Gini evoluiu de 0,62, em 1991, para 0,67, em 2000, e, em 2010, 0,65. Constatou-se assim que, quanto mais próximo de 1,0, maior a concentração de renda. Em paralelo, somente no ano de 2010,53,64\% de toda a renda gerada no Estado ficou concentrada nas mãos dos $10 \%$ mais ricos da população. No Brasil, esse valor é de 48,93\%.

Tal fato pode estar relacionado, possivelmente, tanto ao aumento do desemprego em decorrência do desaquecimento, seguido da crise política observada a partir de 2014, quanto pelas exigências cada vez mais intensas do mercado de trabalho. Concomitantemente, mesmo com um aumento médio de 3,97\% no total de salários pagos no PIM, no período estudado a partir de 2012, o que se observa é uma tendência cada vez mais crescente de redução dos salários pagos. Conforme dados disponibilizados pela Suframa, a redução foi de $6,19 \%$ em 2012, enquanto foi de 30,08\% em 2015 em relação ao ano anterior.

No mesmo sentido, a longevidade, neste estudo representada pela razão entre óbitos e nascidos vivos, aumentou na média de $2,08 \%$ no mesmo período. Isso significa que o total de óbitos aumentou de forma mais do que proporcional em relação aos nascidos. De fato, enquanto o primeiro obteve uma variação média de $3,74 \%$, o total de nascidos vivos cresceu em 1,63\%. 
Tal incremento no indicador pode ser explicado do ponto de vista da redução da taxa de fecundidade, pois esta tem diminuído de forma significativa nos últimos anos. Em 2010, essa taxa era de 2,6\%; já em 1991, era de 4,5\%, de acordo com informações do PNUD.

Por sua vez, o ICMS recolhido pelas atividades do PIM cresceu 1,89\%, em média. O baixo crescimento, em comparação com a evolução do PIB per capita, pode estar relacionado com a sensibilidade em relação às oscilações da conjuntura econômica tanto do ponto de vista interno quanto externo, visto que tem sido constatada uma redução significativa a partir de 2013. Em detalhes, tem-se que a redução, em 2014 , foi de $11,30 \%$ no que se refere ao ano anterior, ao passo que, em 2015, foi de $37,16 \%$.

Em paralelo, no mesmo período, conforme dados da Pesquisa Industrial Anual (PIA/IBGE), o Valor da Transformação Industrial, que corresponde ao valor agregado pelas etapas do processo de produção e parte importante na composição do PIB amazonense, decresceu $0,69 \%$ e $0,35 \%$. Enquanto isso, o total da mão de obra empregada reduziu $13,53 \%$ e $19,06 \%$.

Logo, apesar do aumento do produto e consequentemente da renda per capita no período de crise a partir de 2014, ocorreram reduções significativas na agregação de valor de produção no ICMS recolhido e, principalmente, no total da mão de obra empregada. Tais relações podem ilustrar as implicações das flutuações no ICMS recolhido para variáveis como o produto e o emprego tanto em tempos de aquecimento da economia quanto nos de crise e recessão.

3.2 Modelos de previsão e estimativas para o período 2018-2022

Inicialmente, o primeiro modelo, que trata da previsão do ICMS recolhido pelas atividades do PIM, de forma geral, foi estatisticamente significativo ao nível de 5\%, tendo em vista seu p-valor para a estatística F de 1,35e-11, logo menor do que 0,05\%. Entretanto, a capacidade que cada variável explicativa tem, de forma isolada, em proporcionar uma previsão mais precisa, foi a estatística $t$ de student, em que InLong e InAE não foram estatisticamente significativos ao nível de 5\%, já que seus valores foram de 0,3273\% e 0,0617\%, respectivamente, enquanto $\ln \mathrm{PIBpc}$ e $\ln$ Pop foram significativos, pois obtiveram valores menores que $0,05 \%$.

Por sua vez, de acordo com o coeficiente de determinação $\mathrm{R}^{2}$, nota-se que as variáveis de desenvolvimento humano selecionadas explicam as variações do ICMS recolhido em até $96,66 \%$, enquanto o $\mathrm{R}^{2}$ ajustado foi de $95,82 \%$, o que implica que o modelo em si tem 
capacidade significativa de ser explicado por um ajuste de linha. Por fim, o erro padrão foi de 0,15 .

No tocante às variáveis explicativas, conforme observado no Quadro 1, percebe-se que o ICMS recolhido é muito sensível às variações do PIB per capita, dado que o valor de seu parâmetro foi maior do que 1 . Nesse sentido, um aumento em $1 \%$ no PIB per capita pode acarretar uma elevação do ICMS recolhido em 2,09\%, por exemplo.

\begin{tabular}{|l|c|c|c|c|}
\hline & Coeficiente & Erro Padrão & rácio-t & valor $p$ \\
\hline Const $^{3}$ & 16,4567 & 3,91899 & 4,1992 & 0,00068 \\
\hline $\operatorname{lnPIBpc}{ }^{4}$ & 2,09723 & 0,219287 & 9,5639 & $<0,00001$ \\
\hline $\ln \mathrm{EE}^{5}$ & $-1,52991$ & 0,761731 & $-2,0085$ & 0,06178 \\
\hline $\operatorname{lnLong}$ & $-0,700023$ & 0,692752 & $-1,0105$ & 0,32730 \\
\hline $\operatorname{lnPop}$ & $-0,919035$ & 0,390884 & $-2,3512$ & 0,03186 \\
\hline
\end{tabular}

Quadro 1 - Primeiro modelo - Mínimos Quadrados (OLS), usando as observações 1997-2017 $(\mathrm{T}=21)$. Variável dependente: $\operatorname{lnICMSRec}$. Fonte: Elaboração própria a partir de dados do IBGE, Suframa e Ministério da Saúde - SINASC/SIM.

No caso das demais variáveis explicativas, constatou-se que estas possuem relação inversa, sendo que a referente aos anos de estudo pode proporcionar variações mais do que proporcionais ao ICMS recolhido. Isso pode ser explicado pelo diferencial de desempenho observado entre o recolhimento do imposto em questão e os anos de estudo observados no Gráfico 1. Por conseguinte, a longevidade e a população possuem valores menores que 1, o que significa que uma variação dessas implica impactos menos do que proporcionais à variável explicada pelo modelo.

Sabendo da necessidade de se elaborar um modelo que seja o mais próximo possível da realidade, a realização de testes para verificar a incidência de problemas econométricos é um procedimento importante no tratamento dos resultados da pesquisa. Nesse sentido, foi feito o teste de Fatores de Inflação de Variância (VIF) para verificar a possibilidade de multicolinearidade, que consiste em uma situação na qual uma variável explicativa tem correlação forte com as outras selecionadas para o modelo. Nesse aspecto, os valores VIF maiores que 10,0 podem indicar o problema em questão.

\footnotetext{
${ }^{3}$ Const é um valor real que representa o intercepto da reta com o eixo das ordenadas..

${ }^{4} \ln P$ IBpc corresponde ao Produto Interno Bruto per capita do Estado do Amazonas na função logaritmo neperiano, oriundo das Contas Regionais por meio dos sistemas de dados agregados DataSus, Ipeadata, Estados/IBGE e ESIGA/CEDECTI-AM.

${ }^{5}$ lnAE é a variável anos de estudo da população do Amazonas em logaritmo natural disponibilizada pela PNAD contínua.

${ }^{6}$ lnLong corresponde na razão entre óbitos e nascidos vivos da população do Estado do Amazonas, oriundos dos Sistemas de Informações sobre nascidos vivos e de mortalidade do Ministério da Saúde.

${ }^{7}$ lnPop é a variável população do Amazonas, disponível em Contas Regionais por meio dos sistemas de dados agregados DataSus, Ipeadata, Estados/IBGE e E-SIGA/CEDECTI-AM.
} 
Isso posto, tem-se que o lnPIBpc apresentou um VIF de 12,481, valor levemente acima do aceitável, 10,0. Isso pode estar ligado tanto ao baixo p-valor da estatística t de student para lnLong quanto à possibilidade de o Produto Interno Bruto per capita ter capacidade de ser explicado pelas variações da população. Por outro lado, as demais variáveis tiveram valores VIF < 10; especificamente, 6,91, 7,73 e 7,05 para $\ln \mathrm{AE}$, lnLong e $\ln$ Pop, respectivamente.

O próximo procedimento consiste na elaboração dos modelos referentes às variáveis de desenvolvimento humano. As variáveis estudadas apresentam forte correlação, apresentada na Tabela 1.

\begin{tabular}{|c|c|c|c|c|c|}
\hline & $\ln I C M S-R e c$ & $\ln P I B p c$ & $\ln A E$ & $\ln P o p$ & lnLong \\
\hline lnICMS-Rec & 1 & & & & \\
\hline $\operatorname{lnPIBpc}$ & 0,96248589 & 1 & & & \\
\hline $\ln \mathrm{AE}$ & 0,76447605 & 0,87830757 & 1 & & \\
\hline $\operatorname{lnPop}$ & 0,80544683 & 0,89636846 & 0,82969937 & 1 & \\
\hline lnLong & 0,81529937 & 0,88238363 & 0,88108615 & 0,72070837 & \\
\hline
\end{tabular}

Tabela 1 - Correlação das variáveis PIB per capita, anos de estudo, de longevidade, das variações do ICMS recolhido. Fonte: Elaboração própria a partir de dados do IBGE, Suframa e Ministério da Saúde - SINASC/SIM.

Dado o objetivo da pesquisa e, consequentemente, o método do planejamento em cenários, torna-se necessário verificar as implicações das variações do ICMS recolhido nas variáveis de desenvolvimento humano selecionadas. Conforme descrito na metodologia, isso foi feito por meio de três modelos de regressão linear simples, de acordo com o Quadro 2 a seguir.

Do ponto de vista dos indicadores de sensibilidade, em valores absolutos, os resultados dos parâmetros permitem uma interpretação semelhante ao que foi visto no modelo 1. A exceção é o caso do $\operatorname{lnPIBpc}$, que se mostrou pouco sensível ao lnICMS-rec com um valor de 0,70 . Tal resultado permite verificar que o desempenho do imposto recolhido depende muito mais do PIB per capita do que o caso inverso.

$\mathrm{Na}$ perspectiva da teoria macroeconômica, tais relações fazem sentido, pois a arrecadação de um imposto que incide indiretamente sobre a atividade econômica irá variar tanto em relação às atividades produtivas quanto à demanda dos consumidores por bens e serviços. Em paralelo, os fluxos de produção e consumo serão refletidos e influenciados positivamente por meio de uma maior arrecadação.

\begin{tabular}{|c|c|c|c|c|c|c|c|c|}
\hline $\begin{array}{c}\text { Variável } \\
\text { explicativa }\end{array}$ & Parâmetros & Coeficiente & $\begin{array}{c}\text { Erro } \\
\text { Padrão }\end{array}$ & rácio-t & valor $\mathrm{p}$ & $\mathrm{R}^{2}$ & $\mathrm{~F}(1,19)$ & $\begin{array}{c}\text { Valor P } \\
(\mathrm{F})\end{array}$ \\
\hline \multirow{2}{*}{$\ln \mathrm{PIBpc}$} & $\mathrm{const}$ & $-5,22634$ & $\begin{array}{c}0,94640 \\
4\end{array}$ & $-5,5223$ & 0,00003 & \multirow{2}{0}{$\begin{array}{c}0,92637 \\
9\end{array}$} & $\begin{array}{c}239,078 \\
8\end{array}$ & $\begin{array}{c}3,22 \mathrm{e}- \\
12\end{array}$ \\
\cline { 2 - 9 } & $\operatorname{lnIMSRec}$ & 0,708359 & 0,04581 & 15,4622 & $<0,00001$ & 9 & \\
\hline
\end{tabular}


IMPLICAÇÕES NO ÍNDICE DE DESENVOLVIMENTO HUMANO (IDH) A PARTIR DA PERSPECTIVA

\begin{tabular}{|c|c|c|c|c|c|c|c|c|}
\hline & & & 24 & & & & & \\
\hline \multirow{2}{*}{$\ln \mathrm{AE}$} & const & $-0,521479$ & $\begin{array}{c}0,48194 \\
1\end{array}$ & $-1,0820$ & 0,29278 & \multirow{2}{*}{$\begin{array}{c}0,58442 \\
4\end{array}$} & \multirow{2}{*}{$\begin{array}{c}26,7196 \\
4\end{array}$} & \multirow{2}{*}{$\begin{array}{c}0,00005 \\
5\end{array}$} \\
\hline & InICMSRec & 0,120591 & $\begin{array}{c}0,02332 \\
92\end{array}$ & 5,1691 & 0,00005 & & & \\
\hline \multirow{2}{*}{ lnLong } & const & $-4,85242$ & $\begin{array}{c}0,50324 \\
7\end{array}$ & $-9,6422$ & $<0,00001$ & \multirow{2}{*}{$\begin{array}{c}0,66471 \\
3\end{array}$} & \multirow{2}{*}{$\begin{array}{c}37,6678 \\
8\end{array}$} & \multirow{2}{*}{$\begin{array}{c}6,72 \mathrm{e}- \\
06\end{array}$} \\
\hline & lnICMSRec & 0,149511 & $\begin{array}{c}0,02436 \\
05\end{array}$ & 6,1374 & $<0,00001$ & & & \\
\hline
\end{tabular}

Quadro 2 - Modelos de previsão do PIB per capita, anos de estudo e de longevidade a partir das variações do ICMS recolhido. Fonte: Elaboração própria a partir de dados do IBGE, Suframa e Ministério da Saúde - SINASC/SIM.

Da mesma forma, o maior recolhimento do imposto em questão, mesmo que de forma menos do que proporcional, ainda assim influencia de forma direta os demais indicadores de desenvolvimento selecionados. Isso pode estar relacionado à questão de que, além do ICMS recolhido, outras variáveis podem influenciar a média de anos de estudo, como também a longevidade.

Para analisar as implicações da revogação ou não, torna-se necessário realizar uma previsão desses indicadores de desenvolvimento humano. Isso é projetado para o período 20182022 por meio de um modelo de predição estatístico considerando os devidos testes de significância e de erro já apresentados. O Gráfico 2 ilustra a regressão linear do modelo ICMS ao longo da série histórica de 1997-2017.

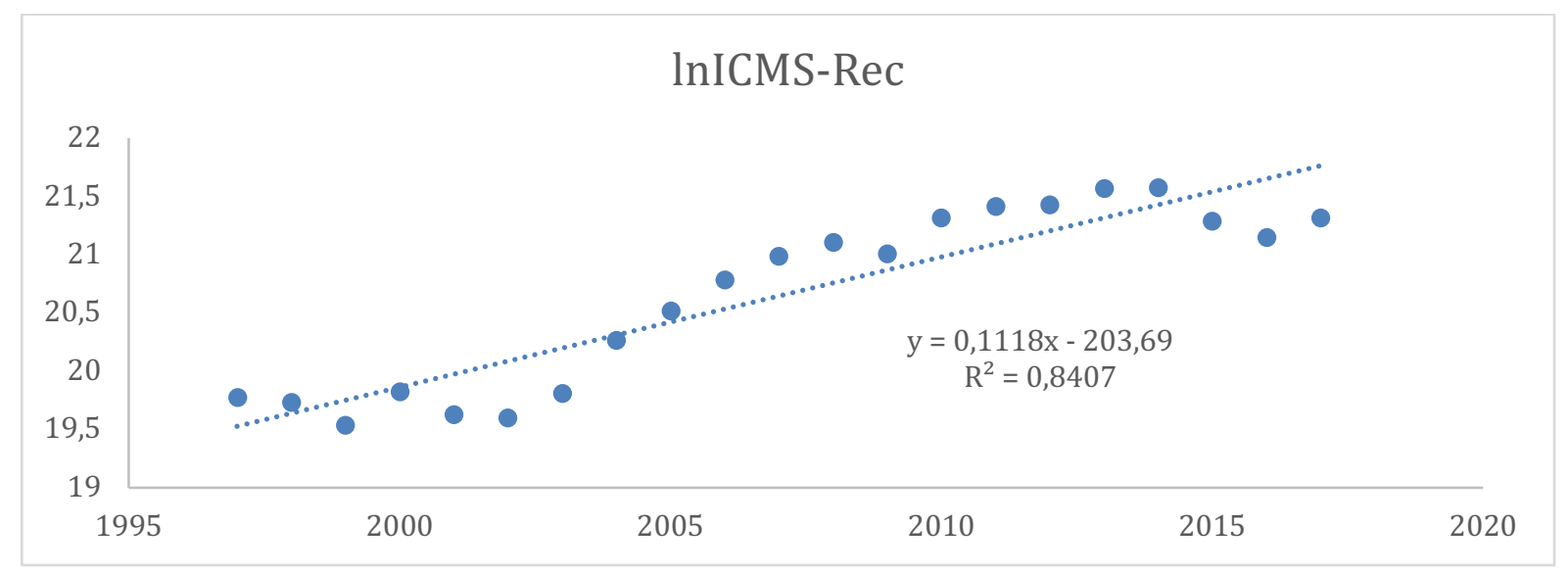

Gráfico 2 - Análise de regressão das variações do ICMS recolhido no período 1997-2017. Fonte: Elaboração própria a partir de dados da Suframa.

Os modelos para previsões foram obtidos por meio das regressões apresentadas no Quadro 2 e pelo modelo gerado do ICMS ilustrado no Gráfico 2 acima. Esses parâmetros são utilizados para gerar as previsões do modelo para o cenário 1 . O resultado está exposto no Quadro 3. 
Além da forte correlação das variáveis estudadas, nota-se, no Quadro 3, que no período previsto os indicadores mostraram uma ascendência, tendo em vista que as variações médias em percentual do período para quase todas as variáveis foram positivas. Dessa forma, houve um impacto para o desenvolvimento humano da região a partir do imposto estudado.

Em se tratando dos cenários que serão levantados, o primeiro diz respeito às variações previstas, considerando que não haja a revogação. Nessa condição, relações verificadas permanecerão no mesmo sentido, ou seja, ficarão mantidas as correlações constatadas na Tabela 1. Por conseguinte, tendo como premissas as variações médias e os modelos estimados, é possível fazer as previsões para o período 2018-2022, conforme explicitado no Quadro 3. Considerando a conjuntura econômica, política e institucional tanto do Estado do Amazonas quanto do Brasil, parte-se do pressuposto de que a variação média venha a ser relativamente baixa ao longo dos anos.

Do ponto de vista das relações entre o ICMS recolhido e as variáveis de desenvolvimento humano observadas nos modelos e a partir dos coeficientes de correlação verificados na Tabela 1, observa-se, no âmbito do cenário 1 , a existência de uma relação bilateral com proporções diferentes, dependendo do sentido da análise. Ou seja, o desempenho no PIB per capita, na média de anos de estudo e na razão entre óbitos e nascidos vivos, influenciará muito mais as variações no recolhimento do imposto do que o contrário, de acordo com o que foi observado nos coeficientes dos parâmetros nos modelos estimados.

\begin{tabular}{|c|c|c|c|c|c|}
\hline Ano & lnICMS-Rec & $\ln$ IBPpc & $\ln \mathrm{AE}$ & $\ln$ Pop & $\operatorname{lnLong}$ \\
\hline 2018 & 21,9224 & 10,4194 & 2,0732 & 15,2922 & $-1,5008$ \\
\hline 2019 & 22,0342 & 10,5077 & 2,0911 & 15,3261 & $-1,4799$ \\
\hline 2020 & 22,1460 & 10,5960 & 2,1090 & 15,3600 & $-1,4590$ \\
\hline 2021 & 22,2578 & 10,6843 & 2,1269 & 15,3939 & $-1,4381$ \\
\hline 2022 & 22,3696 & 10,7726 & 2,1448 & 15,4278 & $-1,4172$ \\
\hline $\begin{array}{l}\Delta \% \text { Média do } \\
\text { período 97/22 }\end{array}$ & $\mathbf{0 , 5 0 \%}$ & $\mathbf{0 , 9 9 \%}$ & $\mathbf{0 , 6 8 \%}$ & $\mathbf{0 , 2 7 \%}$ & $\mathbf{- 1 , 1 9 \%}$ \\
\hline
\end{tabular}

Quadro 3 - Previsão do PIB per capita, anos de estudo, de longevidade e as variações do ICMS recolhido para os próximos 5 anos e variação da média do período 1997-2022. Fonte: Elaboração própria a partir de dados do IBGE, Suframa e Ministério da Saúde - SINASC/SIM.

Por fim, ao se definirem as variáveis críticas para caracterização dos ambientes interno e externo, será possível refazer os modelos, levando em consideração a hipótese de revogação, condição necessária para explicar o cenário 2. Em tal situação, a possibilidade de saída de empresas do PIM pode acarretar aumento do desemprego, da desigualdade e da vulnerabilidade familiar, o que, por conseguinte, implica menor renda, consumo e, por fim, recolhimento do 
ICMS. Em virtude disso, essa situação se reflete nos valores a serem previstos para o período 2018-2022

\section{Conclusão}

Objetivou-se, neste estudo, aprofundar a análise do Índice de Desenvolvimento Humano (IDH) a partir das implicações da revogação da Zona Franca de Manaus em face do Direito Constitucional Tributário, bem como da dimensão tributária do princípio da anterioridade tributária e da isenção do ICMS com base no Código Tributário Nacional, Doutrina e Súmulas do Supremo Tribunal Federal, especificamente a Súmula $n^{\circ}$ 615-STF. Busca-se, desse modo, correlacionar os parâmetros da consolidação das metas do CTN com a legislação de política tributária referente ao ICMS, para se demonstrar as variáveis de desenvolvimento humano enquanto significativas nos compromissos de não revogação do incentivo de isenção do ICMS no polo industrial de Manaus. Sendo assim, inicialmente, será apresentada uma análise sobre os indicadores selecionados até o momento e com as progressões para efetivo estudo e análise, conforme os dados e gráficos apresentados.

Em relação ao IDH, o que se percebe é que, sem o respeito pela vida, pela integridade física e moral do ser humano e das convicções mínimas do poder, e enquanto a liberdade, a autonomia, a igualdade (em direito e dignidade) e os direitos fundamentais não forem reconhecidos e minimamente assegurados, não haverá espaço para a dignidade da pessoa humana, e esta, por sua vez, poderá não passar de mero objeto de arbítrio e injustiças. Nesse caso, existe uma necessidade de reavaliar o modelo da Zona Franca de Manaus/AM, pois é necessário dar mais atenção à sociedade e fazer com que a geração de emprego não vise, como fator principal, o lucro, mas sim o desenvolvimento da região.

Por fim, as dimensões de IDH, educação e longevidade acompanham as tendências apontadas pela variação verificada na população. A média de anos de estudo para as pessoas acima dos 25 anos cresceu em torno de 2,17\% no período 1997-2017, possivelmente devido ao maior acesso ao ensino superior ocorrido a partir dos anos 2000. Apesar do crescimento, este se deu de forma menor do que proporcional ao PIB per capita e em ambiente de um aumento seguido de uma redução pouco significativa da desigualdade, dado observado pelo índice de Gini. 


\section{Referências}

AMARO, L. Direito Tributário brasileiro. 17 ed. Saraiva: São Paulo, 2011.

BRASIL. Código Tributário Nacional - CTN. 3. ed. Lei nº 5.172, de 25 de outubro de 1966. Brasília: Senado Federal, 2017.

BRASIL. Conselho Nacional de Política Fazendária - CONFAZ. Convênio ICMS nº 65 DE 1988/CONFAZ. Publicação DOU de 9 de dezembro de 1988.

BRASIL. Constituição da República Federativa do Brasil. A decisão proferida no Acórdão $\mathrm{n}^{\mathrm{o}} 509$ de 2002 versando sobre o rendimento social de inserção. Brasília: Senado Federal, 1988 .

BRASIL. Constituição da República Federativa do Brasil. Súmula n ${ }^{\circ} 615$ - Supremo Tribunal Federal (STF), de 29 de outubro de 1984. Brasília: Senado Federal, 1988.

BRASIL. Decreto-Lei $\mathbf{n}^{\mathbf{0}} \mathbf{2 8 8}$, de 28 de fevereiro de 1967. Altera as disposições da Lei $\mathbf{n}^{\mathbf{o}}$ 3.173 de 6 de junho de 1957 e regula a Zona Franca de Manaus - ZFM.

BRASIL. Instituto Brasileiro de Geografia e Estatistica - IBGE. Panorama das Cidades Censo de 2010. Disponível em: < https://cidades.ibge.gov.br/brasil/am/panorama $>$. Acesso em: 17 fev. 2020.

BRASIL. Ministério da Economia. Abrangência da Zona Franca de Manaus (ZFM). 2018. Disponível em: <https://www.economia.gov.br>. Acesso em: 15 jan. 2020.

FERREIRA, M. A. M. O desenvolvimento do capitalismo em Manaus. Manaus: UEA, 2003.

GOLDSTEIN, I. Responsabilidade social: das grandes proporções ao terceiro setor. São Paulo: Ática, 2007.

NABAIS, J. C. Direito Fiscal. Biblioteca Nacional de Portugal: Grupo Almedina, 2019.

POMPEU, G. V. M. Crescimento econômico e desenvolvimento humano: entre a soberania do Estado e a proteção os direitos do homem. Revista Pensar, Centro de Ciências Jurídicas da Unifor, Fortaleza, v. 17, n. 1, p. 115-137 / jan-jun, 2012.

SILVA, M. L. A.; Costa, M. F.; LUCAS, M. M. B. Análise do modelo Zona Franca de Manaus com base nas teorias de desenvolvimento regional. IX Seminário Internacional Sobre Desenvolvimento Regional: Processos, Políticas e Transformações Territoriais. Santa Cruz do Sul, RS, Brasil, 11 a 13 de setembro de 2019.

SUFRAMA. Superintendência da Zona Franca de Manaus. Indicadores de agosto. Disponível em: <https://portal1.suframa.gov.br/indicadoresExterno/>. Acesso em 5 fev. 2020.

TOCQUEVILlE, A. A democracia na América: leis e costumes. Tradução de Eduardo Brandão. Livro I. São Paulo: Martins Fontes, 1988. 
VASCONSELOS, A. H. La necesaria armonización del ICMS en Brasil - la experiencia del IVA español como modelo. Tesis Doctoral presentada para obtener el grado de Doctor en Derecho. Universidad de Castilla-La Mancha, España, 2019. Disponível em:

$<$ https://ruidera.uclm.es/xmlui/bitstream/handle/10578/22272/TESIS\%20Vasconselos.pdf?seq uence $=1 \&$ isAllowed=y $>$. Acesso em: 6 fev. 2020.

Data de recebimento: 03.02.2021

Data de aprovação: 20.07.2021 